\title{
Radionuclide Detection of Multiple Soft Tissue Metastases of Osteosarcoma Masquerading as Bone Metastasis
}

\author{
Mustafa Takesh ${ }^{a}$ Henry Zoller ${ }^{a}$ Husam Ghazi ${ }^{b}$ Majdi Zein ${ }^{c}$ Hussam Sahlic $^{c}$ \\ ${ }^{a}$ Department of Nuclear Medicine, University Hospital Heidelberg, Heidelberg, Germany; ${ }^{b}$ Department of Internal \\ Medicine and ${ }^{\mathrm{C} D e p a r t m e n t}$ of Nuclear Medicine, University Hospital, Damascus, Syria
}

\section{Key Words}

Osteosarcoma • Bone scan • Calcified metastases •

Soft tissue metastases

\section{Abstract}

Objective: The aim of this work was to report an unusual case of multiple soft tissue metastases of osteosarcoma detected using bone scan and confirmed by CT scan. Clinical Presentation and Intervention: A 15-year-old patient with a history of osteogenic sarcoma presented with fatigue and loss of appetite in addition to a painless swelling of the distal left lower extremity. Bone scan and chest CT scan were performed for restaging purposes. The bone scan revealed multiple bone metastases and suspected tumor recurrence in the left lower extremity in addition to multiple extraosseous hot spots. The latter findings were assessed as ossified soft tissue metastases after considering the performed CT scan. Conclusion: This case showed the double role of bone scan in osteosarcoma in simultaneously assessing the bone status and tumor spread in soft tissue. The benefit of a comparison of bone scan findings with other modalities was also demonstrated.

Copyright ๑ 2012 S. Karger AG, Basel

\section{Introduction}

Bone scan is of a great value in the evaluation of bone status. Sometimes however, its role can be extended to encompass soft tissue status in certain tumors like osteosarcoma. Unusual sites of soft tissue metastasis had been reported in osteosarcoma including the pleura, pericardium, kidney, adrenal glands and nonregional lymph nodes [1]. These metastases are normally characterized with positive ${ }^{99 \mathrm{~m}} \mathrm{Tc}$ methylene diphosphonate (MDP) uptake. In the presence of multifocal soft tissue metastases especially in the thorax, accompanying multiple bone metastases, the former may be overlooked or misdiagnosed as bone involvement in conventional bone scans, mainly due to its limited spatial resolution.

Considering the proven alteration of prognosis in the presence of regional nodal metastases [2], the demarcation of nonbone metastases could be of prognostic value. We report a case of osteosarcoma with multiple bone metastases in addition to multiple soft tissue metastases observed on bone scan.

\section{KARGER}

Fax +4161306 1234

E-Mail karger@karger.ch

www.karger.com
(C) 2012 S. Karger AG, Basel

1011-7571/12/0216-0582\$38.00/0

Accessible online at:

www.karger.com/mpp
Mustafa Takesh

Robert-Bollschweiler-Strasse 10

DE-69118 Heidelberg (Germany)

Tel. +49 17645387990

E-Mail Mustafa_Takesh@med.uni-heidelberg.de 


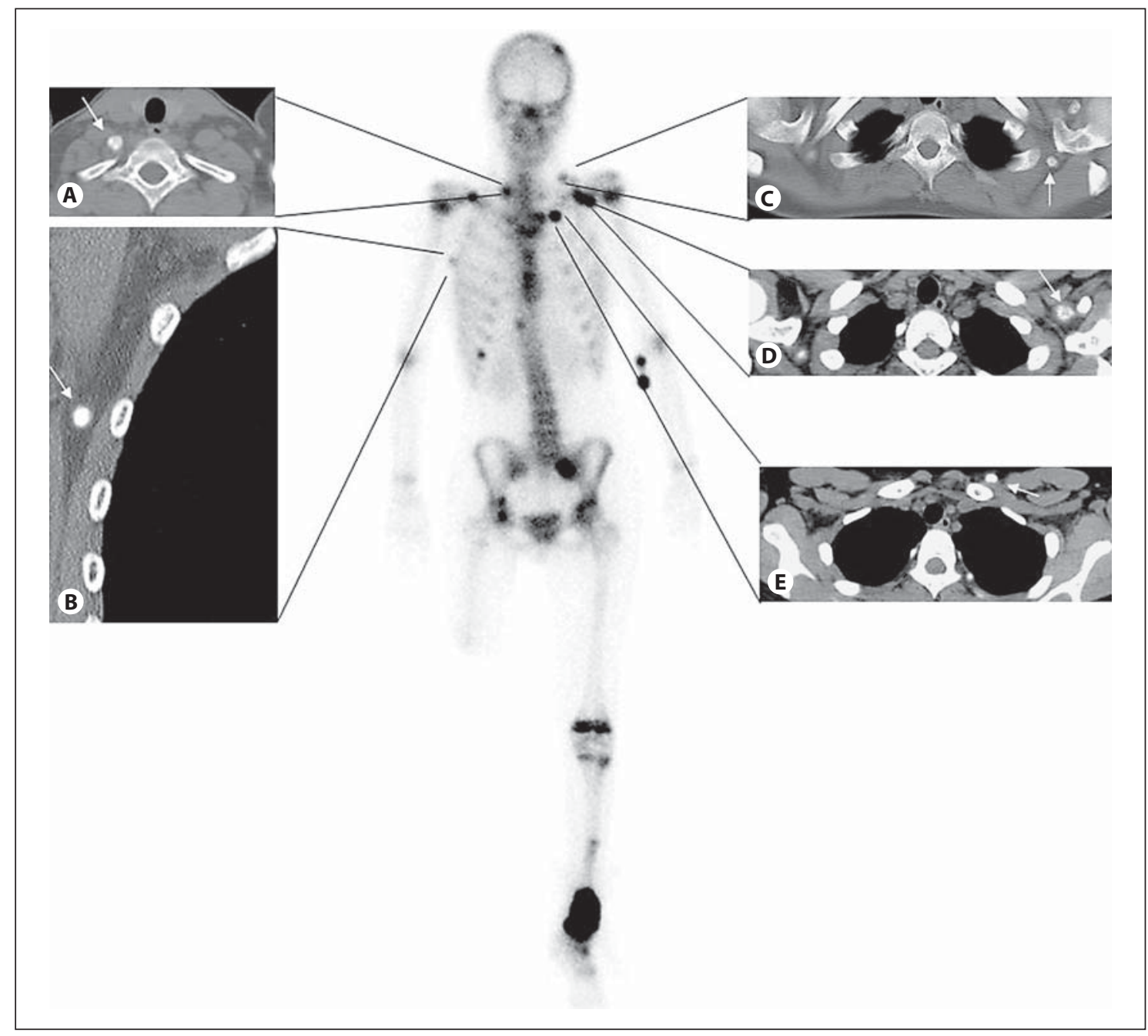

Fig. 1. Bone scan anterior view and corresponding CT images demonstrated the tumor recurrence in the distal left tibia with multifocal intense uptake of $99 \mathrm{mTc}-\mathrm{MDP}$ in particular in the upper thorax matching with multiple calcified soft tissue lesions (arrows) in the muscles $(\mathbf{A}, \mathbf{C})$, lymph nodes (B, D) and subcutaneous layer (E).

\section{Case Report}

A 15-year-old patient was referred to our department to undergo bone scanning for restaging of osteosarcoma, 1.5 years after transfemoral amputation of the right limb. The bone scan revealed tumor recurrence in the distal left tibia, multiple bone metastases, and other focal hot spots similar to bone metastasis and located in the chest wall and neck region (fig. 1). These focal hot spots were first evaluated as bone metastases; however, the extraosseous sites led us to consider additional radiological studies.

Computed tomography of the chest showed that the hotspots on bone scan were multiple soft tissue/visceral metastases including: adrenal gland, chest wall, axillary lymph nodes, shoulder muscles, cervical lymph nodes and mesenteric node (fig. 1). Nevertheless, the detection of soft tissue metastases was not of significant outcome in this patient with end-stage osteosarcoma.

Soft Tissue Metastases of Osteosarcoma Mimicking Bone Metastasis

\section{Discussion}

Extraosseous or soft tissue uptake of ${ }^{99 \mathrm{~m}} \mathrm{Tc}$ diphosphonates is maybe not an unusual finding on skeletal scintigrams in nuclear medicine practice. In the literature, there are many reports describing extraosseous uptakes in a wide variety of benign and malignant disorders such as osteosarcoma. The incidental detection of pulmonary metastases from osteosarcoma using bone scan was frequently reported $[3,4]$. Soft tissue is the next popular site after the lungs for metastasis in osteosarcoma, whereas the lymphatic spread is rare [3-5]. In our case nearly all types of uncommon sites of metastases including visceral, lymph node and skeletal muscle metastases were visu- 
alized in the bone scan, whereas there was no evidence of lung metastases. This is rarely seen in daily clinical practice, according to the spread pattern of osteosarcoma described by Jeffree et al. [6].

Thus, this case described an unusual metastatic pattern, in which the osteosarcoma preferred the soft tissue rather than the lung (the most common metastatic site) $[6,7]$. Karacalioglu et al. [7] mentioned also that extrapulmonary metastatic recurrence is rare.

\section{Pathology and ${ }^{99 m} T c-M D P$ Uptake}

Osteosarcoma had been pathologically divided into three groups depending on the predominant type of matrix (osteoid, fibrous or chondroid matrix) [1]. The presence of mineralized osteoid matrix may explain the osteosarcoma tissue affinity for ${ }^{99 \mathrm{~m}} \mathrm{Tc}-\mathrm{MDP}$. The same applies to the metastases which may contain a sufficient amount of mineralized osteoid matrix $[8,9]$.

Since the scintigraphic appearance of this tumor varies depending on the osteoblastic activity, it is not always possible to detect soft tissue metastases with a low level of osteoblastic activity making the bone scan invalid in evaluating the soft tissue status.

The described soft tissue metastases were initially assessed incorrectly as bone metastasis. Two factors contributed in the false interpretation of these findings; first they share with the simultaneous bone metastases the same appearance, and the poor spatial resolution of bone scans affects negatively the distinction between them.

However, CT of the thorax which was performed principally to exclude lung metastases in the framework of restaging was helpful in showing their nonbone origins. This emphasized the importance of assessing the bone scan findings taking into account the other radiological modalities in particular in the presence of equivocal findings. To distinguish the soft tissue metastases from bone metastases is maybe not of critical clinical relevance for the management in this case, but may have deleterious consequences in other cases of less extended metastatic disease.

\section{Conclusion}

This report emphasized the importance of bone scans in detecting soft tissue metastasis in tumors characterized by calcified metastases such as osteosarcoma. On the one hand, this case shows the benefit of the awareness of other radiological modalities for the precise interpretation of bone scan findings in particular in distinguishing soft tissue metastases from coincident bone metastases.

\section{References}

1 Radhakrishnan VS, Balaji J, Lakshminarasimhan S, Karkuzhali P, Vijayasarathy K: Unusual case of extrapulmonary metastatic recurrence in a patient with osteosarcoma. J Clin Oncol 2011;29:e3-e5.

$>2$ Tobias JD, Pratt CB, Parham DM, Green AA, Rao B: The significance of calcified regional lymph nodes at the time of diagnosis of osteosarcoma. Orthopedics 1985;8:49-52.

$>3$ Petersen M: Radionuclide detection of primary pulmonary osteogenic sarcoma: a case report and review of the literature. J Nucl Med 1990;31:1110-1114.
4 Vanel D, Henry-Amar M, Lumbroso J, et al: Pulmonary evaluation of patients with osteosarcoma: roles of standard radiography, tomography, CT, scintigraphy and tomoscintigraphy. AJR Am J Roentgenol 1984; 143:519-523.

5 Arkader A, Morris CD: Lymphatic spread of pagetic osteogenic sarcoma detected by bone scan. Cancer Imaging 2008;8:131-134.

6 Jeffree GM, Price CH, Sissons HA: The metastatic patterns of osteosarcoma. Br J Cancer 1975;32:87-107.
Karacalioglu O, Ilgan S, Kuzhan O, Emer O, Ozguven M: Disseminated metastatic disease of osteosarcoma of the femur in the abdomen: unusual metastatic pattern on Tc-99m MDP bone scan. Ann Nucl Med 2006;20:437-440.

-8 Zwaga T, Bovée JV, Kroon HM: Osteosarcoma of the femur with skin, lymph node, and lung metastases. Radiographics 2008;28: 277-283.

9 Ozalp N, Sener E, Songur T: Peripheral giant cell granuloma and peripheral ossifying fibroma in children: two case reports. Med Princ Pract 2010;19:159-162. 